13. Fuglsang A, Lomholt M, Gjedde A 1986 Blood-brain transfer of glucose and glucose analogs in newborn rats. $J$ Neurochem 46:1417-1428

14. Cornford EM, Cornford ME 1986 Nutrient transport and the blood-brain barrier in developing animals. Fed Proc 45:2065-2072

15. Wagerle LC, Kumar SP, Belik J, Delivoria-Papadopoulos M 1988 Blood-brain barrier to hydrogen ion during acute metabolic acidosis in piglets. $J$ Appl Physiol 65:776-78

16. Weiss HR 1988 Measurement of cerebral capillary perfusion with a fluorescent label. Microvasc Res 36:172-180

17. Gobel U, Klein B, Schrock H, Kuschinsky W 1989 Lack of capillary recruitment in the brains of awake rats during hypercapnia. J Cereb Blood Flow Metab 9:491-499

18. Klein B, Kuschinsky W, Schrock H, Vetterlein F 1986 Interdependency of local capillary density, blood flow and metabolism in the rat brains. Am J Physiol 251:H1333-H1340
19. Gobel U, Theilen H, Kuschinsky W 1990 Congruence of total and perfused capillary network in rat brains. Circ Res 66:271-281

20. Anwar M, Kissen I, Weiss HR 1990 Effect of chemodenervation on the cerebral vascular and microvascular response to hypoxia. Circ Res 67:1365-1373

21. Weiss HR, Edelman NH 1976 Effect of hypoxia on small vessel blood content of rabbit brain. Microvasc Res 12:305-315

22. Bar T 1980 The Vascular System of the Cerebral Cortex. Springer-Verlag, Berlin

23. David S, Nathaniel EJH 1981 Development of brain capillaries in euthyroid and hypothyroid rats. Exp Neurol 73:243-253

24. Caley DW, Maxwell DS 1970 Development of the blood vessels and extracellular spaces during postnatal maturation of rat cerebral cortex. J Comp Neurol 138:31-48

\title{
Announcement
}

\section{0th Annual Seminar in Pediatric Nephrology}

The 20th Annual Seminar in Pediatric Nephrology: Current Concepts in Diagnosis and Management will be held February 6-10, 1993 at the Fountainebleu Hilton Resort and Spa, Miami Beach, FL. Please contact Pearl Seidler at the University of Miami School of Medicine, Department of Pediatrics, PO Box 016960, Miami, FL 33101, (305) 585-6726, FAX (305) 547-1709. 